\title{
Successful Aging Among Community-Dwelling Older Adults in Urban Areas of Liaoning Province: The Crucial Effect of Visual Ability
}

\author{
Li Liu ${ }^{1,2}$ \\ Tianjiao Zhang ${ }^{3}$ \\ Shuang $\mathrm{Li}^{1,2}$ \\ Guowei $\operatorname{Pan}^{3}$ \\ Lingjun $\mathrm{Yan}^{3}$ \\ Wei Sun (iD) ${ }^{3}$
}

'Institute of Preventive Medicine, China Medical University, Shenyang, Liaoning, I I0I22, People's Republic of China; ${ }^{2}$ Institute of Chronic Diseases, Liaoning Provincial Center for Disease Control and Prevention, Shenyang, Liaoning, I I I200, People's Republic of China ${ }^{3}$ Research Center for Universal Health, School of Public Health, China Medical University, Shenyang, Liaoning, II0I22, People's Republic of China
Correspondence: Wei Sun

Research Center for Universal Health, School of Public Health, China Medical University, No. 77 Puhe Road, Shenyang North New Area, Shenyang, Liaoning,

I I0I22, People's Republic of China

Tel +862431939406

Email wsun@cmu.edu.cn
Purpose: Successful aging is an effective approach to coping with population aging; however, the definition and associated factors vary due to culture and demographic distribution differences. This study was designed to assess successful aging of the older adults in China and explore the associated factors.

Methods: A community-based cross-sectional study was performed in Liaoning, China. After double-cognitive function screening, 3558 older adults (1656 males and 1902 females) $\geq 65$ years of age served as our subjects. Successful aging was assessed based on the following: physical disability; cognitive function; activities of daily living; and self-rated psychological/mood status.

Results: The rate of successful aging was $31.7 \%$ in males and $29.4 \%$ in females. After adjustment for age, multivariate logistic regression showed that successful aging was significantly associated with, in odds ratio sequence, visual ability, self-rated chronic disease, marital status, and filial piety in males, and with visual ability, self-rated chronic disease, watching television, and ethnicity in females.

Conclusion: The level of successful aging in China is lower than in other countries. Demographic characteristics, health status, individual behavior, and social-psychological factors are all associated with successful aging. Overall, visual ability had the most crucial role in successful aging for the older adults, whether males or females.

Keywords: associated factors, older adults, epidemiology, successful aging, visual ability

\section{Introduction}

Since the 21 st century, the world has become an aging society. ${ }^{1}$ The rapid increase in the aging population has presented a serious challenge to human health and social development. According to the China Statistical Yearbook, the number of people $>65$ years of age was $>150$ million in 2016, accounting for $10.8 \%$ of the total population. ${ }^{2}$ The aging population in China is increasing rapidly. Specifically, the one-child policy in China is expected to aggravate the severity caused by aging. Therefore, to improve the quality of life among the older adults and reduce the heavy social pension burden, the WHO and gerontologists have proposed the concept of successful aging (SA). ${ }^{3}$

The term SA was first proposed by Havighurst ${ }^{4}$ in the early 1960 s and focused on life satisfaction. While the Strawbridge's ${ }^{5}$ definition of SA focuses on physical activities. Berkman et $\mathrm{al}^{6}$ took the ability of somatic activities and cognitive function into consideration. As the number of assessed domains increased, 
definitions of SA became more complex and assessment became more comprehensive. According to Rowe and Kahn, ${ }^{7}$ the definition of SA mainly includes the following three criteria: the ability to maintain a low risk of disease and its related disability; high cognitive and physical functional capacity; and active social engagement. It is believed that independent activities of daily living (ADL) are important for the older adults. ${ }^{8}$ According to a survey conducted in Taiwan, ${ }^{9}$ the criteria for SA include complete independence in performing ADL and instrumental activities of daily living (IADL), satisfactory cognitive status (mini-mental state examination $[\mathrm{MMSE}] \geq 24$ ), no depression (Geriatric Depression Scale $<5$ ), and favorable social function (SF subscale $\geq 80$ on SF-36). Currently, the level of education among the older adults in China is uneven or even generally low. ${ }^{10}$ The criteria that require MMSE $\geq 24$ seem to be overly strict. $\mathrm{Li}$ et $\mathrm{al}^{11}$ conducted a study to evaluate SA among the older adults in mainland China, the criteria for which mainly included the following four items: no physical disability; good cognitive function; independent ADL; and good self-rated psychological/ mood status. The criteria and definitions of SA within multiple disciplines vary in the literature, ${ }^{12}$ which might be the reason why studies related to SA are rare both domestically and internationally.

Among the above-mentioned criteria, we do think that the criteria used in the Li study ${ }^{11}$ are more reasonable for mainland Chinese with respect to feasibility and appropriateness. However, the Li study was conducted in 2001, the gross national product, living standards of people, and economic and cultural environment at that time were quite different from the present conditions. In view of the large number of older adults and the rapid pace of aging in China, we believed that it was necessary to conduct this study to assess the status of SA among the older adults and the risk factors based on the current economic and cultural environment. Thus far, research pertaining to $\mathrm{SA}^{5,13-16}$ have revealed that demographic characteristics, health status, behavioral factors, and social-psychological factors are associated with SA. In addition, filial piety is a traditional virtue of the Chinese nation to which the Chinese attach great importance. Therefore, we included filial piety as a relevant factor. We believe our results will clarify the status of SA in Liaoning Province and provide evidence for preserving and promoting active and healthy aging for the older adults with the purpose of reducing the pension burden of the government and coping with population aging.

\section{Materials and Methods}

\section{Study Area and Subjects}

This population-based, cross-sectional study was conducted in urban areas in Liaoning province, which is located in northeast China, serves as an economic and culture hub and includes 14 cities, 56 administrative districts and 611 communities. Shenyang city (9 administrative districts) and Anshan city (5 administrative districts) are the core cities that represent the urban area according to the Liaoning Provincial Yearbook 2012. Two districts in Shenyang city were randomly selected. There is 1 district in Anshan city where minorities gather as an autonomous region. Thus, this district was included. In addition, 1 of 4 administrative districts was randomly selected. Further, one community from each sampled district was randomly chosen. All people $(n=4378)$ who were $\geq 65$ years of age, had lived in the sampled area for $>5$ years, were not diagnosed with dementia, and voluntarily participated in this study comprised the study population. Our study population accounted for $26.7 \%$ of the older adults who had lived in the sampled communities for $>0.5$ year and left for $<0.5$ year. The trained investigators interviewed those participants between March and November 2012. After excluding dropouts because the participants lost patient to or declined to complete $>80 \%$ of the interview, a total of 3838 effective responses were obtained (effective response rate $=87.7 \%$ ). After screening for cognitive impairment using the MMSE, ${ }^{17} 3558$ older adults (1656 males and 1902 females) qualified as our study participants. The sampling frame is shown in Figure 1.

\section{Definition of SA}

The criteria for SA include the following four domains: ${ }^{11}$ (1) No physical disability, which was verified by asking whether or not the subject was traumatized in a traffic accident or in another way. (2) Good cognitive function, which was examined using the MMSE and defined as "good" if the MMSE score was 4 points higher than the cutoff value for cognitive impairment. (3) Independent ADL, which was examined by the Chinese version of the ADL scale. ${ }^{18}$ An individual with an ADL score $\leq 15$ was identified as having independent ADL. (4) Good self-rated psychological/mood status, which was investigated by asking "How often have you felt depressed in the last month?" The 4 responses were "always," "most of time," "much time," and "some time or no." "Good" was defined by an individual answering "some time or no." The SA was defined as "Yes" only if the status for all domains was good. 


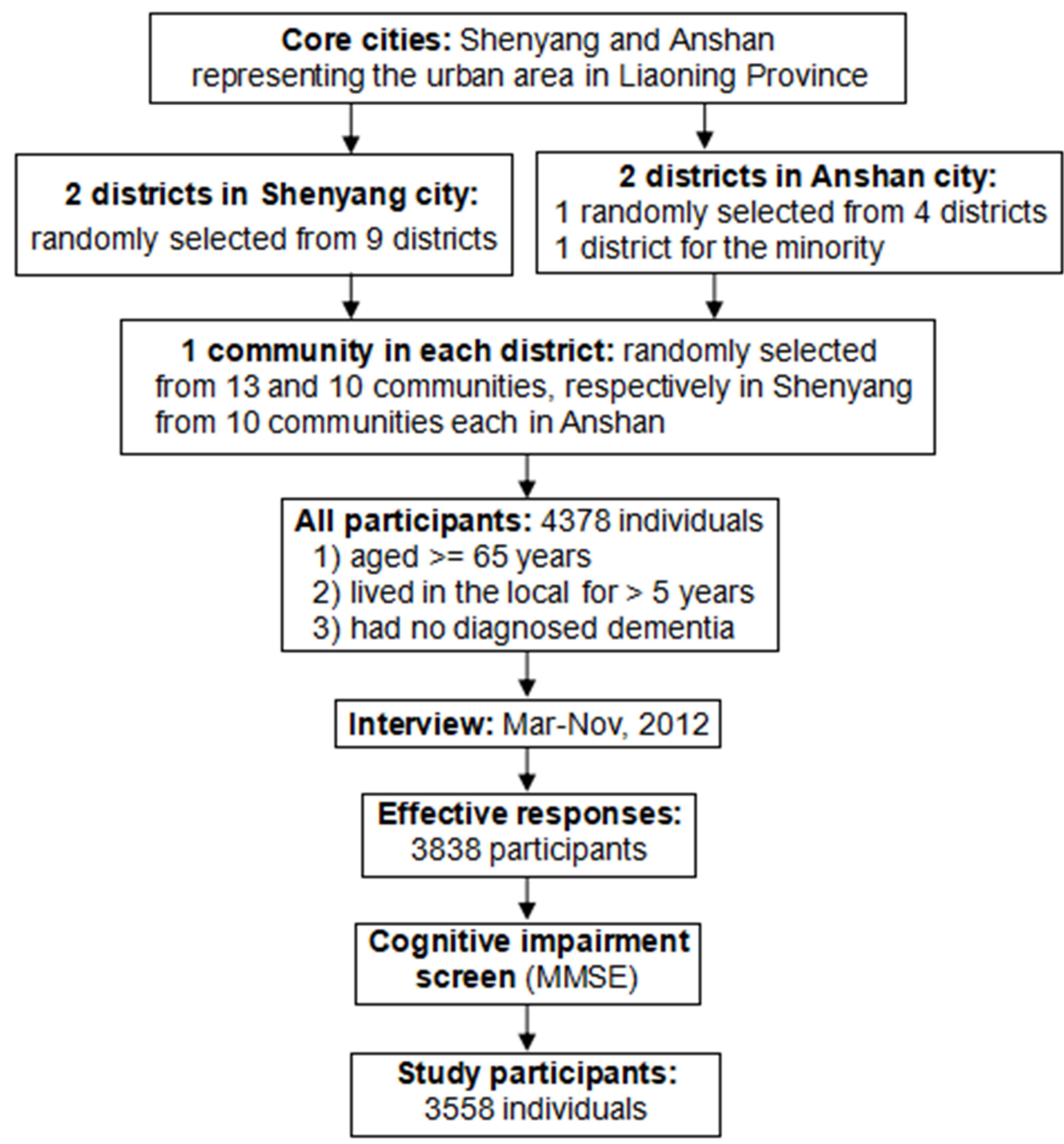

Figure I The sampling frame.

\section{Measurements of Demographic}

\section{Characteristics, Health Status, Behavioral Factors, and Social-Psychological Factors}

Demographic characteristic factors included seven items (age, gender, ethnicity, marital status, living arrangement, health insurance, and pension). ${ }^{19}$ The ethnicity was categorized as "Han" and "minority." Marital status, unmarried, divorce, and separation were combined with widowed as the "other" group due to the low percentage $(<1 \%)$ in the male and female groups. Living arrangement was defined as "living alone" and "living with spouse/ children." Health insurance and pension were measured by asking the subjects if he/she had health insurance or a pension.

Health status contained four items: (1) self-rated chronic disease; (2) visual ability; (3) hearing ability; and
(4) sleep quality. Self-rated chronic disease was categorized as "Present" if hypertension, cardiovascular disease, diabetes, stroke, liver cirrhosis, emphysema, rheumatoid arthritis, or chronic renal insufficiency, had been diagnosed. ${ }^{20}$ The assessment of visual ability, hearing ability, and sleep quality was based on Sun et al. ${ }^{19}$

Behavioral factors comprised four items: (1) smoking; (2) alcohol consumption; (3) taking a walk; and (4) regular diet. Smoking and alcohol consumption were categorized as "yes" or "no." Taking a walk was based on frequency as ">3-4 times/week" or "<2 times/week." "Do you have three meals on time every day" was used to define a regular diet. ${ }^{19}$

Social-psychological factors mainly consisted of three items: (1) participating in entertainment; (2) watching television often; and (3) filial piety. Participating in entertainment and watching television often were categorized 
as "yes" or "no". Filial piety was determined by asking "how good do you feel filial piety from your children?" with four possible answers: "very good," "good," "so so," and "bad". Filial piety was dichotomized as "good" or "so so/bad". ${ }^{19}$

\section{Statistical Analysis}

Data analysis was performed separately in males and females in view of the prominent difference in their life expectancy (75.7 years in males; 80.6 years in females). Among all variables, the items to which $>95 \%$ of subjects had the same responses were excluded from the analysis. In this study, $98.6 \%$ of males and $96.9 \%$ of females had health insurance and $95.8 \%$ of males were of Han ethnicity. Thus, these items were excluded during data analysis. In addition, the individual with missing data were not excluded because the missing data rate was less than $5 \%$. The association between SA and categorical variables including demographic characteristics, health status, behavioral factors, and social-psychological factors was determined using a chi-square test. The risk factors for SA were identified by multivariate logistic regression with adjustment for age. All variables with a $\mathrm{p}<0.25$ became potential candidates for the multivariate model and were entered in the model. Items with a $\mathrm{p}>0.05$ were eliminated in the sequence of $p$ values one at a time. The change in the remaining parameter estimate of maximum likelihood estimates was observed during elimination. The item was clarified as a confounder to remain in the model if the change was greater than $20 \%{ }^{21}$ In this study, no confounders were identified. In addition, the kappa test was applied to clarify the agreement between categorical variables. There were no variables defined in agreement $($ kappa $<0.5) .{ }^{20}$ All statistical analyses were carried out by SAS 9.2.

\section{Results}

Of the 3558 subjects (average age, $73.3 \pm 5.86$ years) enrolled in this study, $33.5 \%$ of males and $41.9 \%$ of females were $\geq 75$ years of age. The distribution of SA by gender and age among the older adults is shown in Table 1. SA had a significant association with age in both males and females. The level of SA in males was higher than females, but the association between SA and gender was not significant. Gender difference of SA was only significant for older adults $>75$ years of age.

The results of univariate analysis of factors that associated with SA are shown in Table 2. For males, all items pertaining to health status and social-psychological factors, demographic characteristics (except for ethnicity), and behavioral factors (except for alcohol consumption and a regular diet), are significantly associated with SA. For females, all items pertaining to demographic characteristics, health status, social-psychological factors, and behavioral factors (except for alcohol consumption) have significant association with SA.

The results of multivariate logistic regression analysis for clarifying the risk factors of SA are shown in Table 3. After adjusting for age in the model, SA in males was significantly associated with visual ability, self-rated chronic disease, marital status, filial piety, watching television often, sleeping quality, hearing ability, taking a walk and participating in entertainment (listed according to decreasing OR). SA in females was significantly associated with visual ability, self-rated chronic disease, watching television often, ethnicity, filial piety, marital status, hearing ability, taking a walk, and sleeping quality.

\section{Discussion}

We used the definition of SA suggested by $\mathrm{Li}$ et $\mathrm{al}^{11}$ to comprehensively assess SA status and identify the associated factors among the older adults in urban areas of

Table I The Distribution of SA by Gender and Age Among the Older Adults in Urban Areas of Liaoning Province

\begin{tabular}{|l|l|l|l|l|l|l|}
\hline \multirow{2}{*}{\multicolumn{2}{|c|}{}} & \multicolumn{2}{|c|}{ Male (N=1656) } & \multicolumn{2}{c|}{ Female (N=1902) } \\
\cline { 3 - 7 } & Yes N (\%) & No N (\%) & Yes N (\%) & No N (\%) \\
\hline Age & $65 ~ 74$ & $404(36.7)$ & $897(63.3)$ & $437(39.5)$ & $668(60.5)$ & ns \\
\hline$P$ & $75+$ & $121(21.8)$ & $434(78.2)$ & $122(15.3)$ & $675(84.7)$ & $<0.01$ \\
\hline Total & \multicolumn{2}{|c|}{$<0.01$} & $559(29.4)$ & $<0.01$ & $1343(70.6)$ \\
\hline
\end{tabular}

Abbreviation: ns, not significant. 
Table 2 Univariate Analysis of Factors Associated with SA

\begin{tabular}{|c|c|c|c|c|}
\hline \multirow[t]{2}{*}{ Variables } & \multicolumn{2}{|c|}{$\operatorname{Male}(N=1656)$} & \multicolumn{2}{|c|}{ Female( $(\mathrm{N}=1902)$} \\
\hline & SA N (\%) & OR (95\% Cl) & SA N (\%) & OR $(95 \% \mathrm{Cl})$ \\
\hline \multicolumn{5}{|l|}{ Demographic characteristics } \\
\hline \multicolumn{5}{|l|}{ Ethnicity } \\
\hline Minority & - & - & $3 I(I I .7)$ & \\
\hline Han & - & - & $527(32.2)$ & $3.61(2.44-5.32)$ \\
\hline Frequency missing & & & \multicolumn{2}{|c|}{ I } \\
\hline \multicolumn{5}{|l|}{ Marital status } \\
\hline Other & $36(12.2)$ & & $65(14.0)$ & \\
\hline Married/cohabitation & $489(36.0)$ & $4.06(2.82-5.85)$ & $494(34.3)$ & $3.20(2.4 I-4.25)$ \\
\hline Frequency missing & \multicolumn{2}{|c|}{1} & & \\
\hline \multicolumn{5}{|l|}{ Living arrangement } \\
\hline Living alone & $22(12.2)$ & & $45(20.0)$ & \\
\hline Living with spouse/children & $503(34.1)$ & $3.72(2.35-5.89)$ & $513(30.7)$ & $1.77(1.26-2.49)$ \\
\hline Frequency missing & \multicolumn{2}{|c|}{2} & \multicolumn{2}{|c|}{4} \\
\hline \multicolumn{5}{|l|}{ Pension } \\
\hline Have not & $19(18.4)$ & & $16(9.4)$ & \\
\hline Have & $505(32.6)$ & $2.14(1.29-3.56)$ & $54 \mid(3 \mid .3)$ & $4.42(2.61-7.46)$ \\
\hline Frequency missing & \multicolumn{2}{|c|}{4} & \multicolumn{2}{|c|}{3} \\
\hline \multicolumn{5}{|l|}{ Health status } \\
\hline \multicolumn{5}{|l|}{ Self-rated chronic disease } \\
\hline Presence & $260(21.8)$ & & $3 \mid 4(2 \mid .3)$ & \\
\hline Absence & $265(57.2)$ & $4.80(3.82-6.04)$ & $245(56.8)$ & $4.85(3.86-6.10)$ \\
\hline \multicolumn{5}{|l|}{ Visual ability } \\
\hline Impaired & $90(13.9)$ & & $85(10.5)$ & \\
\hline Good & $432(43.0)$ & $4.66(3.6 \mathrm{I}-6.0 \mathrm{I})$ & $473(43.5)$ & $6.58(5.10-8.49)$ \\
\hline Frequency missing & \multicolumn{2}{|c|}{5} & \multicolumn{2}{|c|}{4} \\
\hline \multicolumn{5}{|l|}{ Hearing ability } \\
\hline Impaired & $114(15.7)$ & & $107(12.9)$ & \\
\hline Good & $407(44.1)$ & $4.24(3.34-5.38)$ & $45 I(42.1)$ & $4.90(3.87-6.21)$ \\
\hline Frequency missing & \multicolumn{2}{|c|}{6} & \multicolumn{2}{|c|}{5} \\
\hline \multicolumn{5}{|l|}{ Sleeping quality } \\
\hline Bad & $143(19.4)$ & & $190(20.0)$ & \\
\hline Good & $382(4 I .7)$ & $2.96(2.38-3.73)$ & $369(38.8)$ & $2.54(2.07-3.12)$ \\
\hline \multicolumn{5}{|l|}{ Behavioral factors } \\
\hline \multicolumn{5}{|l|}{ Smoking } \\
\hline Yes/had ever & $25 I(26.0)$ & & $101(24.0)$ & \\
\hline Never & $271(39.6)$ & $\mathrm{I} .87(1.5 \mathrm{I}-2.30)$ & $458(30.9)$ & $1.41(1.10-1.81)$ \\
\hline Frequency missing & \multicolumn{2}{|c|}{4} & \multicolumn{2}{|c|}{1} \\
\hline
\end{tabular}


Table 2 (Continued).

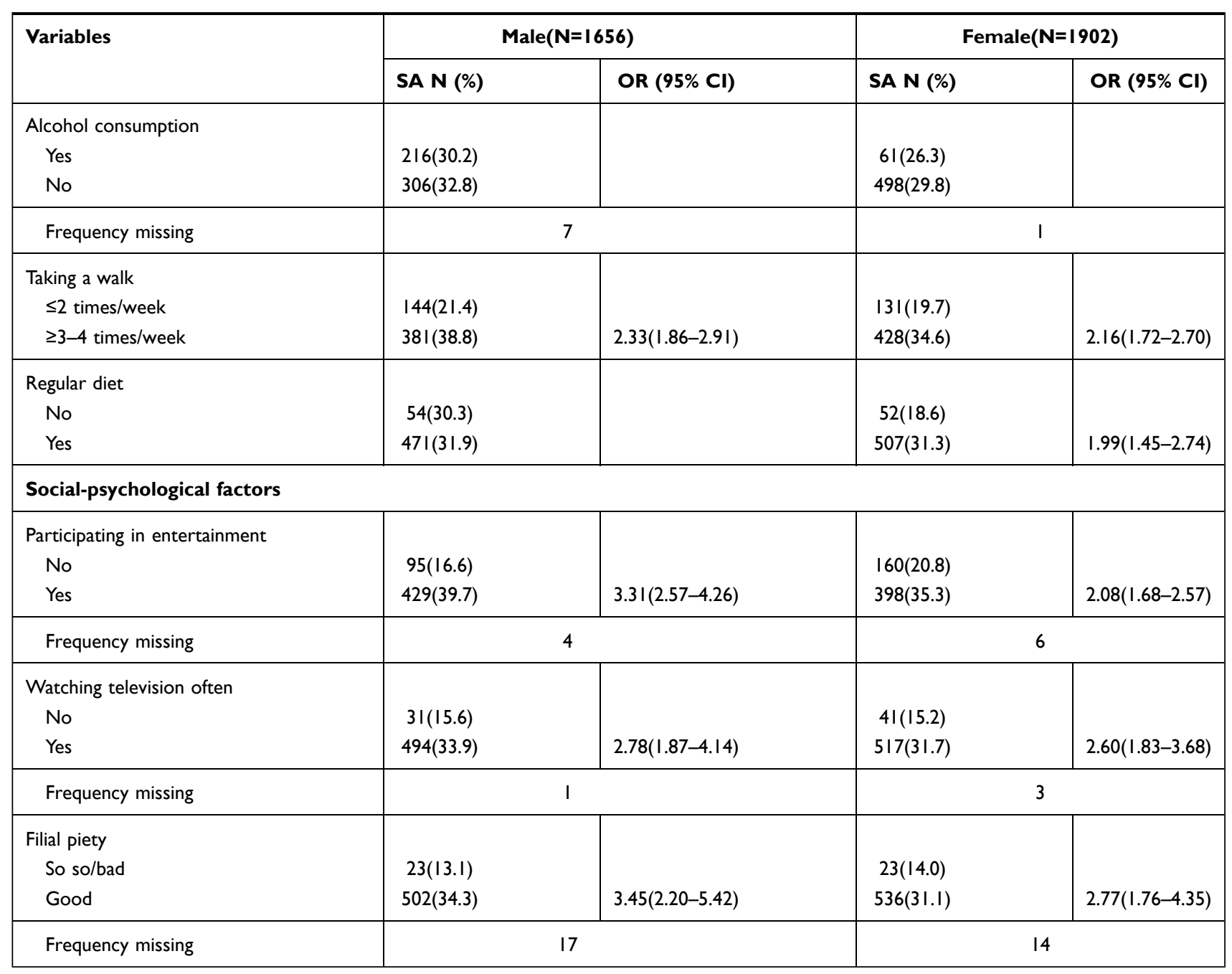

Notes: Frequency missing was shown as the number of missing cases. OR value was only shown for the variables with $p<0.05$.

Liaoning province. A stratified sample method was performed and our study population covered more than $25 \%$ of the older adults who lived in the sampled area regardless of duration of residence. Of the responses, 87.7\% were effective. All of these facts indicated that this population-based study were representative. Also, doublecognitive function screenings (dementia and MMSE screen) were performed, which ensured the exclusion of information bias and increased the credibility of our conclusions.

Among our study population, the SA rate was $30.5 \%$. Visual ability had the strongest association with $\mathrm{SA}$ in both males and females, followed by self-rated chronic disease. Demographic characteristic factors were the second strongest risk factors for SA in males. In contrast, social-psychological factors were the second strongest risk factors in females. With respect to the gender difference in SA, the rate was high in males (31.7\%) compared to females (29.4\%). However, females live longer than males; ${ }^{22}$ thus, there will be more older females with an unhealthy aging status, so we suggest paying more attention to the health of females. Compared to other studies, ${ }^{11,23}$ the SA rate in this study was low. SA represents a relatively independent life within aging period, which is able to reduce age-related problems. With consideration on the fact that the medical expense of the people aged $\geq 65$ years are 3 5 times that of the people aged $<65$ years, ${ }^{24}$ the maintenance of SA has the potential to reduce the heavy pension burden for society. Thus, how to maintain SA among the older adults, especially females, has become a vital and urgent task for us. 
Table 3 Multivariate Logistic Regression Analysis for Clarifying the Risk Factors of SA

\begin{tabular}{|c|c|c|}
\hline Variables & OR & $95 \% \mathrm{Cl}$ \\
\hline \multicolumn{3}{|l|}{ Male $(\mathrm{N}=1629)$} \\
\hline Age (fixed) & 0.99 & $0.96-1.01$ \\
\hline Visual ability (Good vs Impaired) & 3.57 & $2.66-4.78$ \\
\hline Self-rated chronic disease (Absence vs Presence) & 3.31 & $2.52-4.35$ \\
\hline Marital status (Married/cohabitation vs Other) & 2.77 & $1.78-4.33$ \\
\hline Filial piety (Good vs So so/bad) & 2.38 & $1.40-4.07$ \\
\hline Watching television often (Yes vs No) & 2.21 & $1.42-3.46$ \\
\hline Sleeping quality (Good vs Bad) & 1.68 & $1.28-2.20$ \\
\hline Hearing ability (Good vs Impaired) & 1.64 & $1.23-2.20$ \\
\hline Taking a walk ( $\geq 3-4$ times/week vs $\leq 2$ times/week) & 1.57 & $1.20-2.05$ \\
\hline Participating in entertainment(Yes vs No) & 1.51 & $1.13-2.04$ \\
\hline \multicolumn{3}{|l|}{ Female $(\mathrm{N}=1880)$} \\
\hline Age (fixed) & 0.95 & $0.92-0.97$ \\
\hline Visual ability (Good vs Impaired) & 4.44 & $3.33-5.93$ \\
\hline Self-rated chronic disease (Absence vs Presence) & 3.56 & $2.72-4.66$ \\
\hline Watching television often (Yes vs No) & 2.40 & $1.60-3.58$ \\
\hline Ethnicity (Han vs Minority) & 2.14 & $1.36-3.37$ \\
\hline Filial piety (Good vs So so/bad) & 2.11 & $1.24-3.60$ \\
\hline Marital status (Married/cohabitation vs Other) & 2.01 & I.42-2.84 \\
\hline Hearing ability (Good vs Impaired) & 1.61 & $1.21-2.14$ \\
\hline Taking a walk ( $\geq 3-4$ times/week vs $\leq 2$ times/week) & 1.48 & $1.13-1.95$ \\
\hline Sleeping quality (Good vs Bad) & 1.39 & $1.08-1.79$ \\
\hline
\end{tabular}

Note: Age is treated as continuous variable.

With respect to the risk factors for SA, the most influential aspect was shown to be health status. Chronic disease has been verified to be the main threat for the health of the older adults. ${ }^{25}$ In the current study, chronic disease was also found to be crucial for SA. The occurrence of chronic disease leads to a decline in physical functioning; however, one of the most important findings of this study was the crucial role of visual ability, which was shown to be the strongest influential factor for SA in older males and females. The effect of visual ability is even stronger than chronic disease. With aging, organ function deteriorates and the incidence of visual impairment among the older adults increases. ${ }^{26}$ It has been reported that visual impairment has an impact on the physical and mental health of the older adults, ${ }^{27}$ including depression and reduced life satisfaction, affecting participation in social activities and independent ADL. Interestingly, a previous study $^{8}$ on SA also explored the impact of visual ability, but the effect was not strong, possibly because of different evaluation criteria. They graded the visual ability according to an objective ophthalmic examination. We paid more attention to the functional evaluation, thus the impact of visual ability on ADL. Generally, the damage caused by decreased vision often occurs before the ophthalmic examination. Many older adults do not pay attention to declining vision, and do not go to the hospital for ophthalmic examinations in a timely fashion. ${ }^{28}$ In addition, hearing ability and sleep quality were also shown to be related to SA. Hearing impairment indicates that the sensory ability is damaged, which plays a negative role in the communication between the individual and the outside world. Sleep is an important process by which individuals recover physical strength and spirit. Adequate, good sleep can effectively maintain and regulate health and restore mental well-being. Thus, improving the health status of the older adults, preventing chronic disease, keeping sound hearing ability and good sleep quality, and especially maintaining good visual ability, are helpful to achieve SA.

Demographic characteristic factors were also shown to have a strong association with SA. Marital status had a significant effect on SA in both males and females. Especially in males, the effect was only next to health status as a factor influencing SA. It might be because the 
traditional concepts of Chinese "male outside and female stay", ${ }^{29,30}$ females in Chinese families take on more housework and care more for the daily life of their families, while males rely more on spouses and family support. ${ }^{31}$ Encouraging widowed or single older adults to remarry, having a complete family, and companionship of spouses facilitate SA in the older adults. In addition, we found that ethnicity only affected older females, because in this study, only $4.17 \%$ of the male subjects were minorities. Therefore, the effect of ethnicity on older males has not been evaluated.

With respect to social-psychological factors, filial piety was shown to have an effect on SA for older males and females. Related research has indicated that filial piety from offspring has considerable effect on the physical and mental health status of the older adults and could have an impact on life satisfaction. ${ }^{32}$ Another socialpsychological factor was watching television often. The effect involved older males and females, especially females, its effect was second only to health status. In China, females tend to benefit more from watching television than males due to the above-mentioned concepts of Chinese "male outside and female stay". The older an individual is, the deeper the effect of this traditional concept. As a result, older females have fewer outdoor activities to contact society in comparison to males, and watching television appears to become a prominent approach to society for them. In contrast, in addition to watching television, participating in entertainment, such as going fishing or playing cards or chess, in the spare time was also able to affect SA among older males. Thus, encouraging filial piety, advocating the older adults to watch television moderately as a leisure activity and actively participate in varieties of entertainment could be conducive to raise the SA rate.

With respect to behavior factors, taking a walk was shown to play a role in SA for both males and females. Even if there are many forms of physical exercise to perform, taking a walk is a particularly feasible and safe for the older adults as a means of exercising. Thus, it was selected as an indicator of exercise in this study. Research has shown that taking a walk to exercise slows down the speed of declining physical function and is advantageous to achieving $\mathrm{SA}^{33}$ Therefore, we advocate that older adults take regular walks.

There were several limitations in the present study. First, the measure of some items, such as smoking, alcohol consumption, and self-rated chronic disease, were rough.
These items were attained by interviewing the participants, which may weaken the assessment of their effects. The older adults are not likely to smoke heavily or drink alcohol excessively, and we have asked the subjects if their self-rated chronic diseases were diagnosed. Second, we used the MMSE to perform double-cognitive function screening to exclude the cognitive impairment subjects, which may overestimate the rate of SA. Patients with cognitive impairment, who could not accurately answer the questions in the questionnaire, will bring great information bias, which will affect the credibility of the conclusion. So, we chose to exclude them, even though this will lead to an overestimate of the rate of SA. Third, our study participants were voluntary. The individuals with voluntary awareness tend to be active and in good health status. As a result, the prevalence of chronic disease was in a very low level $(28.0 \%$ in males and $22.7 \%$ in females). In addition, among 14 cities in Liaoning Province, only 2 cities were sampled. All of these facts might weaken the representativeness of the sample. Fourth, this study was a cross-sectional design. It is difficult to determine causality between SA and identified factors. A longitudinal study is needed to confirm all findings.

\section{Conclusion}

We chose a relatively scientific and feasible, but not overly strict criteria to determine the level of SA among the community-dwelling older adults in urban areas of Liaoning province for the first time and identify its associated factors. Compared with other developed regions, the $\mathrm{SA}$ in Liaoning province is at a relatively low level. We explored out that the visual ability has the most crucial effect on SA in both males and females. Hence, according to our study, visual health support, prevention of chronic disease, encouraging widowed or single older adults to remarry, and filial piety should be chiefly considered when improving the level of SA. Our findings suggest that there should be a focus on a SA program by the health promotion strategies for the aged population. The maintenance of SA could facilitate a good and positive life during the aging period and achieve improvement in the quality of life among older adults.

\section{Data Sharing and Data Accessibility}

The data that supports the findings of this study are available from the corresponding author upon reasonable request. 


\section{Ethics Statement}

The study protocol and informed consent form received ethics approval from the Ethics Committee of China Medical University. All procedures were adherence to the guidelines of the Declaration of Helsinki. Written informed consent concerning conduct of the survey was obtained from each participant.

\section{Acknowledgments}

The authors would like to thank all the members of Community Committee who helped to get the written informed consent about the conduct of this survey.

\section{Author Contributions}

All authors made substantial contributions to conception and design, acquisition of data, or analysis and interpretation of data; took part in drafting the article or revising it critically for important intellectual content; agreed to submit to the current journal; gave final approval of the version to be published; and agree to be accountable for all aspects of the work.

\section{Funding}

This work was supported by the [National Natural Science Foundation of China] under Grant [number: 81102193].

\section{Disclosure}

Dr Wei Sun reports Government Support from National Natural Science Foundation of China, during the conduct of the study. The authors declare that there is no conflict of interest.

\section{References}

1. Anisimov VN, Sidorenko AV. It is necessary to establish an international agency for research on aging. Aging. 2018;10(5):863-867. doi:10.18632/aging.101451

2. National bureau of statistics of China. China Statistical Yearbook, 2017. China Statistics Press; 2017.

3. Shi WH, Zhang HY, Zhang J, et al. The status and associated factors of successful aging among older adults residing in longevity areas in China. Biomed Environ Sci. 2016;29(5):347-355. doi:10.3967/ bes2016.045

4. Havighurst RJ. Successful aging. Gerontologist. 1961;1:8-13. doi:10.1093/geront/1.1.8

5. Strawbridge WJ, Cohen RD, Shema SJ, et al. Successful aging: predictors and associated activities. Am J Epidemiol. 1996;144 (2):135-141. doi:10.1093/oxfordjournals.aje.a008900

6. Berkman LF, Seeman TE, Albert M, et al. High, usual and impaired functioning in community-dwelling older men and women: findings from the MacArthur Foundation Research Network on successful aging. J Clin Epidemiol. 1993;46(10):1129-1140. doi:10.1016/08954356(93)90112-e
7. Rowe JW, Kahn RL. Human aging: usual and successful. Science. 1987;237(4811):143-149. doi:10.1126/science.3299702

8. Chen XJ, Wang XX, Qiu CX, et al. Study on the status of daily activities and its countermeasures among the elderly people in community. Mod Prev Med. 2017;44:255-258.

9. Lin PS, Hsieh CC, Cheng HS, et al. Association between physical fitness and successful aging in Taiwanese older adults. PLoS One. 2016;11(3):e0150389. doi:10.1371/journal.pone.0150389

10. Liu YB, Liu L, Li YF, et al. Relationship between health literacy, health-related behaviors and health status: a survey of elderly Chinese. Int J Env Res Pub He. 2015;12(8):9714-9725. doi:10.3390/ijerph120809714

11. Li CB, Zhang XK, Zhang MY. The successful senior cirigen: a the preliminary study of the discriminating standard and correlated factors of success. Chinese $J$ Gerontol. 2000;20:67-69+127. doi:10.3969/j.issn.1005-9202.2000.02.002

12. Depp CA, Jeste DV. Definitions and predictors of successful aging: a comprehensive review of larger quantitative studies. Am J Geriatr Psychiatry. 2006;14(1):6-20. doi:10.1097/01.JGP.0000192501.03069.bc

13. Li CI, Lin CH, Lin WY, et al. Successful aging defined by health-related quality of life and its determinants in community-dwelling elders. BMC Public Health. 2014;14:1013. doi:10.1186/1471-2458-14-1013

14. Feng Q, Son J, Zeng Y. Prevalence and correlates of successful ageing: a comparative study between China and South Korea. Eur J Ageing. 2015;12(2):83-94. doi:10.1007/s10433-014-0329-5

15. Shafiee M, Hazrati M, Motalebi SA, et al. Can healthy life style predict successful aging among Iranian older adults? Med J Islam Repub Iran. 2020;34:139. doi:10.34171/mjiri.34.139

16. Chia EM, Mitchell P, Rochtchina E, et al. Association between vision and hearing impairments and their combined effects on quality of life. Arch Ophthalmol. 2006;124(10):1465-1470. doi:10.1001/ archopht.124.10.1465

17. Zhang AP, Yang DL. Investigation of cognitive ability among people in the elderly housing in Chongqing. Chinese J Gerontol. 2009;29 (15):1943-1945.

18. Chen $\mathrm{P}, \mathrm{Yu}$ ES, Zhang M, et al. ADL dependence and medical conditions in Chinese older persons: a population-based survey in Shanghai, China. J Am Geriatr Soc. 1995;43(4):378-383. doi:10.1111/j.1532-5415.1995.tb05811.x

19. Sun W, Aodeng S, Tanimoto Y, et al. Quality of life (QOL) of the community-dwelling elderly and associated factors: a population-based study in urban areas of China. Arch Gerontol Geriatr. 2015;60(2):311-316. doi:10.1016/j.archger.2014.12.002

20. Wang B, Wu Y, Zhang T, Han J, Yu L, Sun W. Effect of physical activity on independent living ability among community-dwelling elderly in urban areas of Liaoning Province in China: a population-based study. BMJ Open. 2019;9(10):e023543. doi:10.1136/bmjopen-2018-023543

21. Sun W, Watanabe M, Tanimoto Y, et al. Factors associated with good self-rated health of non-disabled elderly living alone in Japan: a cross-sectional study. BMC Public Health. 2007;7(1):297. doi:10.1186/1471-2458-7-297

22. Le Y, Ren J, Shen J, Li T, Zhang CF. The changing gender differences in life expectancy in Chinese cities 2005-2010. PLoS One. 2015;10(4):e0123320. doi:10.1371/journal.pone.0123320

23. Li C, Wu W, Jin H, et al. Successful aging in Shanghai, China: definition, distribution and related factors. Int Psychogeriatr. 2006;18(3):551-563. doi:10.1017/S1041610205002966

24. Li H. Population aging, medical burden and investment in micro human capital. Statistics \& Decision. 2021;37(2):88-92. doi:10.13546/j.cnki.tjyjc.2021.02.019

25. Chen XH, Lu ZX. Impact of chronic diseases on activity of daily living in community-dwelling elderly patients. Nurs J Chinese People Liberation Army. 2009;26(14):19-22. doi:10.3969/j. issn.1008-9993.2009.14.007 
26. Braithwaite T, Verlander NQ, Bartholomew D, et al. The National Eye Survey of Trinidad and Tobago (NESTT): Rationale, Objectives and Methodology. Ophthalmic Epidemiol. 2017;24(2):116-129. doi:10.1080/09286586.2016.1259639

27. Ribeiro MV, Hasten-Reiter Júnior HN, Ribeiro EA, Jucá MJ, Barbosa FT, Sousa-Rodrigues CF. Association between visual impairment and depression in the elderly: a systematic review. Arq Bras Oftalmol. 2015;78(3):197-201. doi:10.5935/0004-2749.20150051

28. Liu SM, Yan SG, Gong L. The survey of old people' vision and oculopa in the suburbs of Jinan home care center. Chinese Nurs Res. 2014;28(32):4079-4081.

29. Yang XF, Yang MH, Wang ZY, Sun J. Investigation and research on the entertainment activities of urban elderly from the perspective of aging. Chinese Gen Pract Nurs. 2017;15(07):864-866. doi:10.3969/j. issn.1674-4748.2017.07.041
30. Li X, Ma XX, Kong LL, Wang J, Zhang ZX. Survey of demand on cultural and recreational activities of community elderly in Xianning city. Chinese Nurs Res. 2016;30(05):612-614. doi:10.3969/j. issn.1009-6493.2016.05.033

31. Fu J. Studies on gender differences in dependency among the elderly in China [dissertation]. Southwest Univ Financ Econ. 2016.

32. Chen WW. The relationship between perceived parenting style, filial piety, and life satisfaction in Hong Kong. J Fam Psychol. 2014;28 (3):308-314. doi:10.1037/a0036819

33. Sabia S, Singh-Manoux A, Hagger-Johnson G, Cambois E, Brunner EJ, Kivimaki M. Influence of individual and combined healthy behaviours on successful aging. CMAJ. 2012;184 (18):1985-1992. doi:10.1503/cmaj.121080

\section{Publish your work in this journal}

Risk Management and Healthcare Policy is an international, peerreviewed, open access journal focusing on all aspects of public health, policy, and preventative measures to promote good health and improve morbidity and mortality in the population. The journal welcomes submitted papers covering original research, basic science, clinical \& epidemiological studies, reviews and evaluations, guidelines, expert opinion and commentary, case reports and extended reports. The manuscript management system is completely online and includes a very quick and fair peer-review system, which is all easy to use. Visit http://www.dovepress.com/testimonials.php to read real quotes from published authors. 